\title{
Baclofen-Associated Onset of Central Sleep Apnea in Alcohol Use Disorder: A Case Report
}

\author{
Lampros Perogamvros $^{a}$ Jean Louis Pépin ${ }^{a, f}$ Gabriel Thorens ${ }^{b}$ \\ Pierre Mégevand $^{c, g} \quad{\text { Elisabeth } \text { Claudel }^{\mathrm{a}} \text { Fabrice Espa }}^{\mathrm{a}}$ Marie Besson ${ }^{\mathrm{d}}$ \\ Katerina Cervena ${ }^{a}$ Jean-Paul Janssens ${ }^{\mathrm{e}}$ Frédéric Lador $^{\mathrm{a}} \mathrm{e}$ \\ a Sleep Laboratory and ${ }^{b}$ Addictology Unit, Department of Psychiatry and Mental Health, ' Division of Neurology, \\ Department of Clinical Neurosciences, ${ }^{d}$ Department of Clinical Pharmacology and Toxicology and Regional \\ Pharmacovigilance Centre, and ${ }^{e}$ Division of Pulmonology, Department of Medicine Specialties, Geneva \\ University Hospitals, Geneva, Switzerland; f Pôle Thorax et Vaisseaux, Secteur Physiologie Sommeil et Exercice, \\ Laboratoire EFCR, Inserm U1042, HP2, Grenoble University Hospital, Université Grenoble Alpes, Grenoble, France; \\ ${ }^{9}$ Neurosurgery Department, Hofstra North Shore-LIJ School of Medicine and Feinstein Institute for Medical \\ Research, Manhasset, N.Y., USA
}

\section{Established Facts}

- Baclofen is a $\mathrm{GABA}_{\mathrm{B}}$ agonist increasingly used in the management of alcohol use disorder.

- The potential deleterious effect of baclofen on breathing physiology during sleep has not been fully described.

\section{Novel Insights}

- Central sleep apnea is a potential adverse event of high-dose baclofen treatment.

- Sleep-disordered breathing should be weighed and carefully monitored when considering the use of baclofen in patients with alcohol use disorder.

\section{Key Words}

Baclofen · Alcohol use disorder - Central sleep apnea syndrome

This study was performed at the Sleep Laboratory of the Geneva University Hospitals.

\section{Abstract}

A 61-year-old patient with alcohol use disorder (AUD) was referred for suspicion of sleep apnea syndrome (SAS). He had incurred three road accidents attributed to sleepiness over the previous year, shortly after initiation of high-dose (100 mg b.i.d.) treatment with baclofen, a molecule increasingly used in the management of AUD. Polysomnography revealed a severe central SAS (CSAS) with an apnea-hypopnea index (AHI) of $81.6 / \mathrm{h}$. Baclofen was suggested as a possible

\section{KARGER 125}

E-Mail karger@karger.com www.karger.com/res
(C) 2015 S. Karger AG, Base

0025-7931/15/0906-0507\$39.50/0
Frédéric Lador, $\mathrm{MD}, \mathrm{PhD}$

Service de Pneumologie et Laboratoire du Sommeil

Hôpitaux Universitaires de Genève 4, rue Gabrielle Perret-Gentil

CH-1211 Geneva 14 (Switzerland)

E-Mail frederic.lador@hcuge.ch 
cause of the CSAS, and after its withdrawal, a second polysomnography was done, showing the disappearance of the central apneas and a shift to severe obstructive SAS (AHI $43.9 / \mathrm{h}$ ), for which a positive airway pressure (CPAP) treatment was initiated. A third polysomnography was performed under CPAP after reintroduction of baclofen $(50 \mathrm{mg}$ b.i.d.) by the patient, showing reappearance of the CSAS (AHI 42.1/h). This case report illustrates the deleterious effect of baclofen on breathing physiology during sleep. Since it is typically prescribed off label at high doses to a population of patients potentially using other substances that inhibit the ventilatory drive, this possible adverse effect is a major concern. When considering the use of baclofen in patients with AUD, the potential for sleep-disordered breathing should be weighed and carefully monitored.

(c) 2015 S. Karger AG, Base

\section{Introduction}

Over the past 10 years, there has been widespread interest in the role of the $\mathrm{GABA}_{\mathrm{B}}$ receptor in the control of alcohol use-related behaviors. In this context, baclofen, a $\mathrm{GABA}_{\mathrm{B}}$ agonist, has been increasingly used at high doses in the management of alcohol use disorder (AUD). However, little is known about the potential effects of this offlabel treatment on breathing physiology during sleep.

\section{Case Report}

A 61-year-old patient with AUD was referred to the sleep laboratory for suspicion of sleep apnea syndrome (SAS) because of snoring, poor sleep quality and sleepiness [Epworth Sleepiness Scale (ESS) score 11/24]. Over the previous year, he had incurred three road accidents attributed to sleepiness. It seemed likely that these events were related to sleep-disordered breathing. For 2 years, he had been on high-dose baclofen, which helped him to decrease alcohol consumption from 140-160 to 40-60 g/day. He was treated only with baclofen $(100 \mathrm{mg}$ b.i.d.) when we performed a first polysomnography (PSG) (fig. 1).

Respiratory parameter measurements and event scoring were performed according to the current recommendations [1]. The sensors used were an oronasal thermal sensor and a nasal pressure transducer for airflow as well as calibrated dual thoracoabdominal respiratory inductance plethysmography belts for respiratory effort. Oxygen saturation was obtained by continuous pulse oximetry, and ventilatory status by continuous transcutaneous capnography $\left(\mathrm{PtcCO}_{2}\right)$. PSG revealed a severe central SAS (CSAS) with an apnea-hypopnea index (AHI) of $81.6 / \mathrm{h}$ (table 1). $\mathrm{PtcCO}_{2}$ was normal, with no argument for hyper- or hypoventilation according to the current definitions [1]. The clinical examination was unremarkable and showed no sign of neurological or cardiac disease that could explain the presence of CSAS. The chest auscultation
Table 1. PSG reports

\begin{tabular}{llll}
\hline & PSG 1 & PSG 2 & PSG $3^{\mathrm{a}}$ \\
\hline Sleep study & & & \\
Total sleep time, min & 485.5 & 539.5 & 531.5 \\
Sleep efficacy, \% & 86.3 & 88.8 & 89.1 \\
N1 sleep latency, min & 5.4 & 11.6 & 0.5 \\
REM sleep latency, min & 243.3 & 114.5 & 113.0 \\
\hline Respiration, n/h & & & \\
Obstructive apnea & 0.0 & 0.3 & 0.0 \\
Obstructive hypopnea & 10.6 & 39.5 & 19.2 \\
Central apnea & 69.7 & 3.9 & 42.1 \\
Central hypopnea & 1.0 & 0.0 & 0.3 \\
AHI & 81.6 & 43.9 & 61.6 \\
ODI & 81.2 & 24.4 & 40.6 \\
PLM & 8.2 & 7.8 & 4.1 \\
\hline SpO ${ }_{2}, \%$ & & \\
Awake & 93.2 & 93.3 & 95.2 \\
Sleep (mean) & 92.3 & 92.9 & 94.4 \\
Sleep (minimum) & 82.0 & 88.0 & 86.0 \\
\hline PtcCO 2 mm Hg & & & \\
Awake & 41.9 & 36.0 & 40.5 \\
Sleep (mean) & 42.0 & 38.1 & 42.5 \\
Sleep (maximum) & 45.0 & 42.4 & 48.2 \\
\hline
\end{tabular}

PSG 1: baclofen $200 \mathrm{mg} /$ day and alcohol 4-6 U/day; PSG 2: alcohol 14-16 U/day; PSG 3: baclofen $100 \mathrm{mg} /$ day, alcohol 6-8 U/day and auto-cPAP. N1 = Stage $1 ; \mathrm{REM}=$ rapid eye movements; ODI = oxygen desaturation index; PLM = periodic limb movements. ${ }^{\text {a }}$ PSG 3 was performed while the patient was on fixed CPAP.

results and oxygen saturation were normal. The body mass index was 24.4. An echocardiography showed no sign of left or right ventricular dysfunction, and a normal left ventricular ejection fraction. A cerebral CT scan was normal. We thus considered baclofen as a possible cause of CSAS.

A few weeks after its withdrawal, the consumption of alcohol, a known risk factor for obstructive SAS, increased again to 140160 g/day. A second PSG (fig. 1) showed a shift toward a typical severe obstructive SAS (AHI 43.9/h) (table 1). The patient was initiated on continuous positive airway pressure (CPAP) treatment (REMstar auto, Respironics) in the auto-adjusting mode (autocPAP, with a pressure range of $5-15 \mathrm{~cm} \mathrm{H}_{2} \mathrm{O}$ ). Two months after CPAP initiation, the patient noted a marked improvement in symptoms (ESS score 6/24). The reports downloaded from the device showed a satisfactory compliance $(7 \mathrm{~h} /$ night $)$ and a normalization of the AHI (1.9/h; mean pressure $\left.7.0 \mathrm{~cm} \mathrm{H}_{2} \mathrm{O}\right)$ without persistent central events. At the 6-month clinical follow-up, the patient's comfort and compliance ( $4.3 \mathrm{~h} / \mathrm{night})$ had decreased, and the mean pressure applied had increased to $9.6 \mathrm{~cm} \mathrm{H}_{2} \mathrm{O}$. Moreover, the CPAP download reports showed an increase in AHI (20.8/h) with detection of a Cheyne-Stokes respiration pattern (fig. 2). The patient acknowledged that, unbeknown to us, he had gone back on baclofen (50 mg b.i.d.) and had decreased alcohol consumption (60-80 g/day). The clinical examination was unchanged. The 


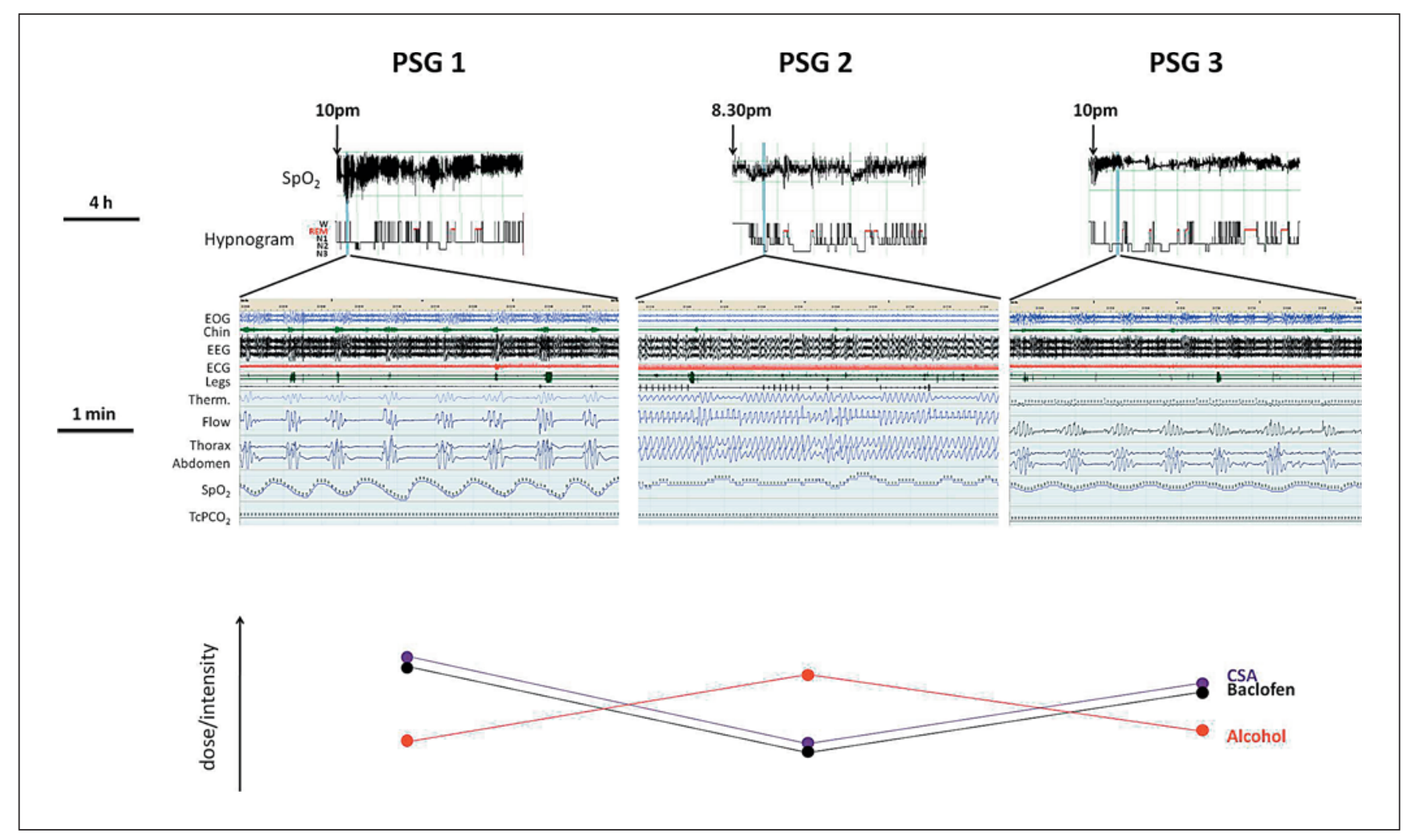

Fig. 1. Typical respiratory pattern as recorded during the PSG. Fiveminute sequences showing CSA during nREM sleep (PSG 1), obstructive hypopnea during nREM sleep (PSG 2) and CSA during nREM sleep (PSG 3). The relative intensity of CSA and the relative dose changes of baclofen and alcohol intake are represented at the bottom of the figure. PSG 3 was performed while the patient was on

CPAP mode was fixed $\left(10 \mathrm{~cm} \mathrm{H}_{2} \mathrm{O}\right)$ to improve the patient's comfort. A third PSG (fig. 1) with CPAP showed the reappearance of a severe CSAS (AHI 42.1/h) (table 1); the ESS score was now 10/24. Baclofen was again stopped, and the subsequent CPAP download reports showed a resolution of the central events over 1 week with a residual obstructive AHI of 3.1/h.

\section{Discussion}

This case report strongly suggests a causal relationship between high-dose baclofen and CSAS. The occurrence of central apneas was most probably baclofen induced, as withdrawal of this drug resulted in their disappearance, while its reintroduction reinstalled a severe CSAS under CPAP. Moreover, the patient had no cardiac or neurological disease and took no other medication with documented side effects on sleep-related breathing. Alcohol fixed CPAP. CSA = Central sleep apnea; $\mathrm{nREM}=$ non-rapid eye movement; EOG = electro-oculogram; Chin = chin muscle activity; EEG = electroencephalogram; ECG = electrocardiogram; Legs = leg muscle activity; Therm. $=$ nasal thermistance; Flow $=$ nasal flow; Thorax/Abdomen $=$ thoracic/abdominal belts; $\mathrm{TcPCO}_{2}=\mathrm{PtcCO}_{2}$.

consumption was negatively correlated with central apneas, arguing against a direct causal relationship, even if a potential influence of alcohol cannot be ruled out with certainty. Indeed, the patient was still using alcohol together with baclofen treatment (40-60 g/day), which may have increased his vulnerability to sleep-related breathing disorders. Finally, CSAS was probably not generated by CPAP therapy (treatment-emergent CSAS), as the use of auto-CPAP without baclofen during several weeks was characterized by a perfect control of respiratory events.

The main known side effects of baclofen, $\mathrm{GABA}_{B}$ agonist, are sedation and excessive sleepiness. Animal and human studies have demonstrated that baclofen significantly prolongs total sleep time, while sleep fragmentation is reduced [2-4]. In a double-blind, placebo-controlled, cross-over study of a single dose of baclofen (25 $\mathrm{mg}$ ) administered before sleep to 10 snoring subjects with mild-to-moderate sleep-disordered breathing (AHI 


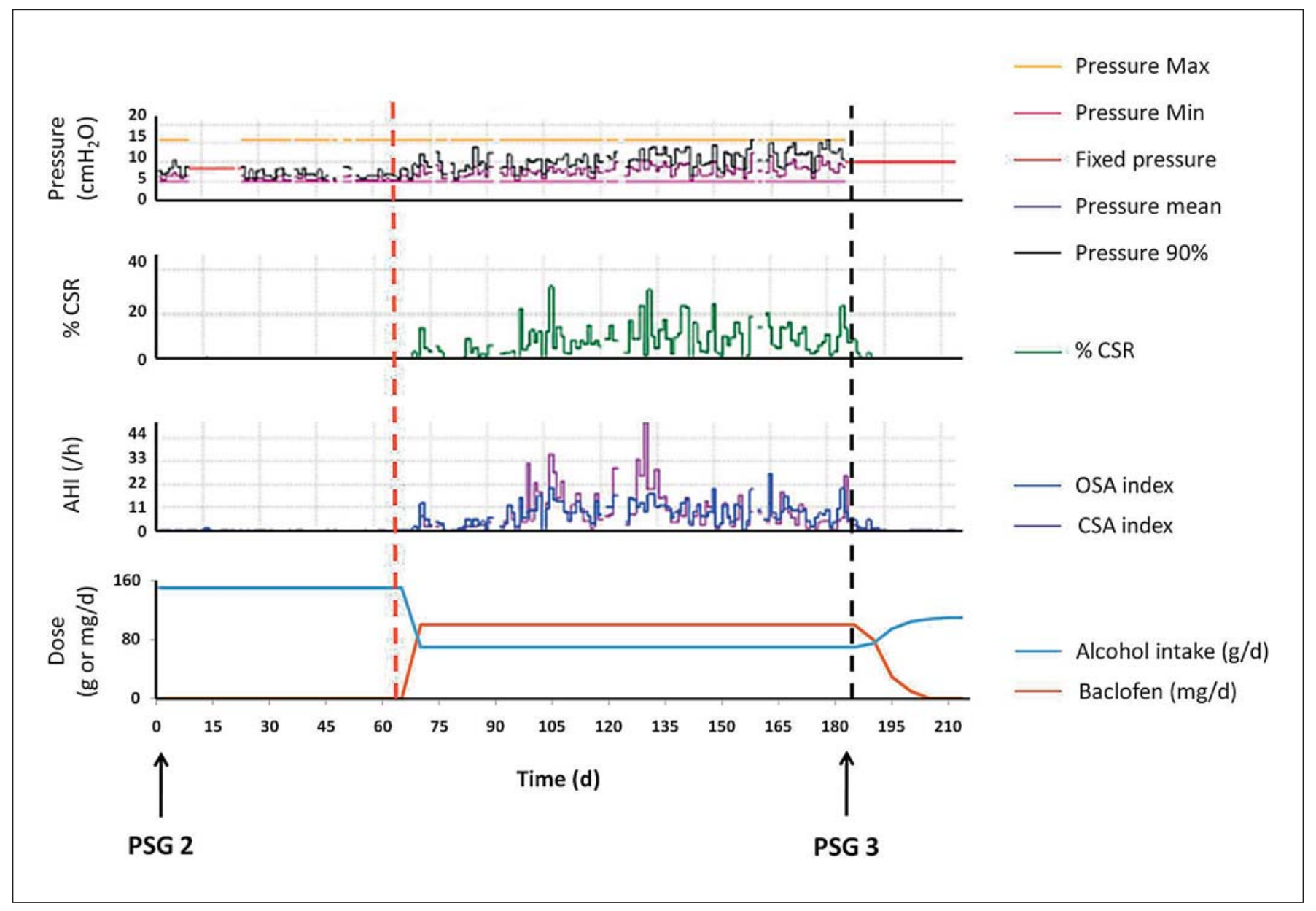

Fig. 2. Report of the evolution of pressure, the percentage of detected CSR and residual obstructive or central events (AHI) from the CPAP device. Note the increase in central events detected after the reintroduction of baclofen 2 months after CPAP initiation (red dashed line) and the return to normal values within 1 week after its withdrawal (black dashed line). The dose changes of baclofen and alcohol intake are represented at the bottom of the figure. PSG 3 was performed while the patient was on fixed CPAP. CSR = Cheyne-Stoke respiration; OSA = obstructive sleep apnea; CSA = central sleep apnea; $d=$ day.
$<30 / \mathrm{h}$ ), there was a marginal impairment in nocturnal oxygen saturation $\left(\mathrm{SpO}_{2}\right)$, with an insignificant trend toward more apneas or hypopneas [2]. It was hypothesized that the reduction in $\mathrm{SpO}_{2}$ was due to a decrease in minute ventilation resulting from a reduction in ventilation drive as reflected in blunted ventilatory responses to $\mathrm{CO}_{2}$ produced by $\mathrm{GABA}_{\mathrm{B}}$ agonism, as found in animals $[5,6]$. Intrathecal baclofen (162-237 $\mu \mathrm{g} /$ day, concentration 500 $\mu \mathrm{g} / \mathrm{ml}$ ) in patients with severe spasticity induced a significant increase in central sleep apnea after a drug bolus administration but not during continuous administration [7]. It was hypothesized that - as opposed to continuous administration - a direct effect of a bolus administration of baclofen on the central ventilatory drive may explain these observations. The oral intake may have been high enough here to trigger the same effect. Such a reduction in ventilatory drive, related to the inhibition of both resting ventilation and the slope of the ventilatory response to $\mathrm{CO}_{2}$, may be analogous to the inhibition of cardiovascular centers when GABA is administered at the ventral brainstem level [8]. It was also reported that intoxication with a high dose of baclofen induced a decrease in respiratory rate and coma, probably by directly depressing spinal cord inspiratory neurons [9]. It therefore appears that the pathophysiology of baclofen-related central sleep apnea differs from that suggested for patients with heart failure $[10,11]$. This is of importance as the management of drug-induced CSAS may include adap- 
tive servoventilation, a treatment that is contraindicated in central sleep apnea associated with heart failure since the recent release of results of a large clinical trial [12].

This is a significant concern, as baclofen is increasingly used in the management of AUD. In fact, several reports have strongly suggested that baclofen can be efficiently used for alcohol withdrawal syndrome in humans [13-16]. In addition, it has been shown that highdose baclofen (75-400 mg/day) achieves and maintains alcohol abstinence and reduces craving for alcohol [1416]. It is, however, noteworthy that not all randomized, placebo-controlled studies support the efficacy of baclofen in AUD [17]. Thus, baclofen has not yet been recommended in Europe or in the USA for the treatment of AUD (DSM-5). However, its off-label administration has progressively emerged and, without any official approval or guidelines about its use, arbitrary prescription practices have developed. French alcohol specialists currently prescribe baclofen to almost 100,000 AUD sufferers, typically at off-label high doses [18]. This practice may spread in the future, as it has already been reported in other European countries, Australia and in the USA.

This case report illustrates the deleterious effect of baclofen on breathing physiology during sleep. Since it is typically prescribed off label at high doses to a population of patients potentially using other substances that already inhibit the ventilatory drive (i.e. alcohol or benzodiazepines), this possible adverse effect is of major concern. When considering the use of baclofen in patients with AUD, the potential for sleep-disordered breathing should be weighed and carefully monitored. Further studies are needed to confirm the direct causal relationship between baclofen and CSAS.

\section{Financial Disclosure and Conflicts of Interest}

The authors have no conflicts of interest related to the present study.

\section{References}

1 Berry RB, Budhiraja R, Gottlieb DJ, et al: Rules for scoring respiratory events in sleep: update of the 2007 AASM Manual for the Scoring of Sleep and Associated Events. Deliberations of the Sleep Apnea Definitions Task Force of the American Academy of Sleep Medicine. J Clin Sleep Med 2012;8:597-619.

-2 Finnimore AJ, Roebuck M, Sajkov D, McEvoy $\mathrm{RD}$ : The effects of the GABA agonist, baclofen, on sleep and breathing. Eur Respir J 1995;8:230-234.

- 3 Hodor A, Palchykova S, Gao B, Bassetti CL: Baclofen and gamma-hydroxybutyrate differentially altered behavior, EEG activity and sleep in rats. Neuroscience 2015;284:18-28.

4 Vienne J, Lecciso G, Constantinescu I, et al: Differential effects of sodium oxybate and baclofen on EEG, sleep, neurobehavioral performance, and memory. Sleep 2012;35:10711083.

5 Hedner J, Hedner T, Wessberg P, Jonason J: An analysis of the mechanism by which gamma-aminobutyric acid depresses ventilation in the rat. J Appl Physiol Respir Environ Exerc Physiol 1984;56:849-856.

-6 Kneussl MP, Pappagianopoulos P, Hoop B, Kazami H: Reversible depression of ventilation and cardiovascular function by ventriculocisternal perfusion with gamma-aminobutyric acid in dogs. Am Rev Respir Dis 1986; 133:1024-1028.
7 Bensmail D, Marquer A, Roche N, et al: Pilot study assessing the impact of intrathecal baclofen administration mode on sleep-related respiratory parameters. Arch Phys Med Rehabil 2012;93:96-99.

-8 Yamada KA, Norman WP, Hamosh P, Gillis RA: Medullary ventral surface GABA receptors affect respiratory and cardiovascular function. Brain Res 1982;248:71-78.

-9 Weisshaar GF, Hoemberg M, Bender K, Bangen U, Herkenrath P, Eifinger F, Rothschild M, Roth B, Oberthuer A: Baclofen intoxication: a 'fun drug' causing deep coma and nonconvulsive status epilepticus - a case report and review of the literature. Eur J Pediatr 2012;171:1541-1547.

10 Fox H, Puehler T, Schulz U, et al: Delayed recovery from Cheyne-Stokes respiration in heart failure after successful cardiac transplantation: a case report. Transplant Proc 2014;46:2462-2463.

-11 Fox H, Bitter T, Horstkotte D, Oldenburg O: Termination of adaptive servoventilation after successful long-term therapy. Case report of a heart failure patient with nocturnal Cheyne-Stokes respiration. Herz 2014;39:8789.

12 Cowie MR, Woehrle $\mathrm{H}$, Wegscheider $\mathrm{K}$, et al: Rationale and design of the SERVE-HF study: treatment of sleep-disordered breathing with predominant central sleep apnoea with adaptive servo-ventilation in patients with chronic heart failure. Eur J Heart Fail 2013;15:937943.
13 Addolorato G, Leggio L, Abenavoli L, et al: Baclofen in the treatment of alcohol withdrawal syndrome: a comparative study versus diazepam. Am J Med 2006;119:276.e13-e18.

14 Rigal L, Alexandre-Dubroeucq C, de Beaurepaire R, et al: Abstinence and 'low-risk' consumption 1 year after the initiation of highdose baclofen: a retrospective study among 'high-risk' drinkers. Alcohol Alcohol 2012;47: 439-442.

15 Addolorato G, Leggio L, Ferrulli A, et al: Dose-response effect of baclofen in reducing daily alcohol intake in alcohol dependence: secondary analysis of a randomized, doubleblind, placebo-controlled trial. Alcohol Alcohol 2011;46:312-317.

16 Addolorato G, Leggio L, Ferrulli A, et al: Effectiveness and safety of baclofen for maintenance of alcohol abstinence in alcohol-dependent patients with liver cirrhosis: randomised, double-blind controlled study. Lancet 2007; 370:1915-1922.

17 Garbutt JC, Kampov-Polevoy AB, Gallop R, Kalka-Juhl L, Flannery BA: Efficacy and safety of baclofen for alcohol dependence: a randomized, double-blind, placebo-controlled trial. Alcohol Clin Exp Res 2010;34:18491857.

18 Rolland B, Paille F, Fleury B, et al: Off-label baclofen prescribing practices among French alcohol specialists: results of a national online survey. PLoS One 2014;9:e98062.
Baclofen-Associated Onset of CSAS in Alcohol Use Disorder 